
graduado en Historia por la Universidad de San Pablo y doctor en relaciones internacionales, dentro de esta disciplina, por la Universidad de Brasilia. Vivió durante tres años en Paraguay, lo que supuso su acercamiento a la evolución histórica del país y a la investigación de la memoria de la Guerra de la Triple Alianza. De esta investigación surgieron sus obras dedicadas a la Guerra Grande, con una visión científica muy diferente a la que generalmente ha venido considerándose como válida. Prueba de su afán erudito son sus libros La guerra del Paraguay y Maldita Guerra, su último y muy comentado trabajo, donde nos ofrece su interpretación a través del proceso histórico regional, rechazando la tesis de la responsabilidad absoluta del imperialismo inglés en el conflicto, entre otras ideas que demuestra a lo largo de su ya amplia bibliografía.

1

CUNNINGHAME GRAHAM, Robert Bontine. Retrato de un ditador; Francisco Solano López (1865-1870). Buenos Aires: Inter-Americana, 1943.

2

PASTORE, Carlos. La lucha por la tierra en el Paraguay. Montevideo: Antequera, 1972, pp. $148-150$.

El nacionalismo lopizta paraguayo FRANCISCO F. MONTEOLIVA DORATIOTO

\title{
EL NACIONALISMO LOPIZTA PARAguayo
}

\author{
FRANCISCO FERNANDO MONTEOLIVA DORATIOTO
}

El nacionalismo paraguayo, predominante durante el siglo XX, se confunde con la exaltación de la figura de Francisco Solano López. Ese nacionalismo dominó el mundo político y cultural paraguayo, distinguiéndose a menudo por la apología del autoritarismo militarista y estatista y por la xenofobia.

En marzo de 1870, las tropas brasileñas mataron a Solano López en Cerro Corá, lo cual puso fin a la guerra entre la Triple Alianza y el Paraguay (1865-1870). Hasta fines del siglo XIX, no se dudaba en calificar de dictador al que había sostenido una guerra de su país contra vecinos más poderosos. En Retrato de un dictador: Francisco Solano López, Robert Bontine Cunninghame Graham relata su viaje al Paraguay en 1871 y el odio de los supervivientes hacia López.

Hacia fines del siglo XIX, Paraguay era paupérrimo, falto de autoestima y carente de héroes paradigmáticos. Había triunfado la ideología liberal, cuyos seguidores despreciaban el pasado despótico y a los antiguos gobernantes. En aquel entonces, empezaba a sobresalir una generación de estudiantes universitarios y bachilleres. Era un grupo pequeño y concentrado en Asunción, que anhelaba la construcción de un sociedad mejor, aunque no disponía de un pensamiento capaz de recuperar la autoestima nacional y a la vez encontrar la solución para una realidad miserable. Esos jóvenes buscaban héroes que encarnaran los valores, supuestos o verdaderos, de la nacionalidad paraguaya. La educación liberal no les ofrecía sino la denuncia de los «antihéroes» que gobernaron el país como dictadores hasta 1870 .
Esas circunstancias viabilizaron el nacimiento en el Paraguay del revisionismo histórico de la figura de Solano López, también conocido por lopizmo. Ese movimiento tenía por objeto transformar la imagen de Solano López de dictador responsable por el estallido de una guerra desastrosa para su país en héroe valeroso y patriótico y víctima de la agresión de la Triple Alianza.

Si bien es cierto que el revisionismo histórico lopizta llenó un vacío ideológico en $\mathrm{Pa}$ raguay, otro fue el motivo de su presentación en la sociedad paraguaya. Al llegar a Paraguay a fines de la década de 1850, Elisa Lynch, compañera de Solano López, no tenía recursos. Durante la guerra, ella compró tierras de gran extensión y varios bienes raíces urbanos. Aunque se dio a conocer la versión de compra, la verdad es que el gobierno paraguayo le regaló 33.175 kilómetros cuadrados del territorio que era objeto de litigio con Brasil; 4.375 entre los ríos Bermejo y Pilcomayo, área reconocida como argentina en la posguerra $y$ 135.000 en la región oriental de Paraguay. Además, Lynch compró 29 bienes inmuebles, de los cuales 27 se ubicaban en Asunción ${ }^{2}$. El enriquecimiento inmobiliario de madame Lynch, como la llamaban los paraguayos por aquel entonces, fue posible porque el estado paraguayo era prácticamente un feudo de la familia López.

En diciembre de 1868, Solano López declaró a Elisa Lynch su heredera universal. Al volver a Europa después de la guerra, Lynch quedó en la pobreza tras el despilfarro de la herencia en París, donde pasó a vivir, y en viaje al cercano oriente. Empobrecida, Elisa 
Lynch intentó, en 1885, tomar posesión de las tierras que le habían sido transferidas. Debido a los tratados de límites firmados en la posguerra, las tierras habían sido repartidas entre Paraguay, Argentina y Brasil. En virtud de la dificultad para alcanzar su objetivo, ella transfirió sus supuestos derechos a su hijo mayor, Enrique Venancio Solano López. Sin embargo, tales derechos no han sido reconocidos por las autoridades judiciales de esos países.

La denegación por parte de las autoridades judiciales paraguayas tenía el respaldo legal de tres decretos dictados por el poder ejecutivo entre 1869 y 1870 . Se había declarado a Solano López traidor de la patria y proscrito. Sus bienes y los de sus parientes fueron embargados, incluso los de la «concubina» Elisa Lynch por el origen «bastardo y ilegítimo» (sic). Los bienes del ex dictador fueron transferidos al estado. Las propiedades de Elisa Lynch, anteriores a las «donaciones» o "compras» de la etapa final de la guerra, fueron embargadas. Al aprobar los tres decretos, el poder legislativo paraguayo bloqueó estratagemas jurídicas de las que podrían valerse sus herederos para reclamar esas propiedades.

Enrique Venancio Solano López procuró, entonces, alejar los obstáculos legales para intentar cambiar el fallo de la justicia paraguaya contrario a su pretensión de recibir los bienes de los cuales sus padres se habían adueñado. Ese es el hecho que explica el nacimiento del revisionismo lopizta que vinculó el nacionalismo a Francisco Solano López. Un informe sobre la situación política del Paraguay, elaborado en 1931 por la Legación brasileña en Asunción, saca a la luz el nacimiento del revisionismo lopizta y explica la transformación de Juan Emiliano O’Leary de crítico en panegirista de Solano López. O'Leary fue el intelectual impulsor del nacimiento del revisionismo para «recuperar» la memoria del fallecido dictador, retratándolo como héroe. O'Leary fue tan exitoso en la tarea de reivindicar esa recuperación que le apodaron El Reivindicador.

El informe diplomático brasileño asevera que los herederos de Solano López, interesados en recuperar sus bienes, se pusieron de acuerdo con los paraguayos influyentes con miras a lograr la revocación del decreto de 1869 y recobrar sus derechos civiles. Una vez que se alcanzara tal objetivo y se creara un ambiente político favorable, sería posible contra-

rrestar los obstáculos jurídicos para que los descendientes de Solano López y Elisa Lynch lograran la devolución de las propiedades y bienes que pertenecían a su padres. «El señor O'Leary se puso a defender los intereses lopiztas inconfesables de dinero» $y$ se mantuvo en ello al darse cuenta que podría obtener

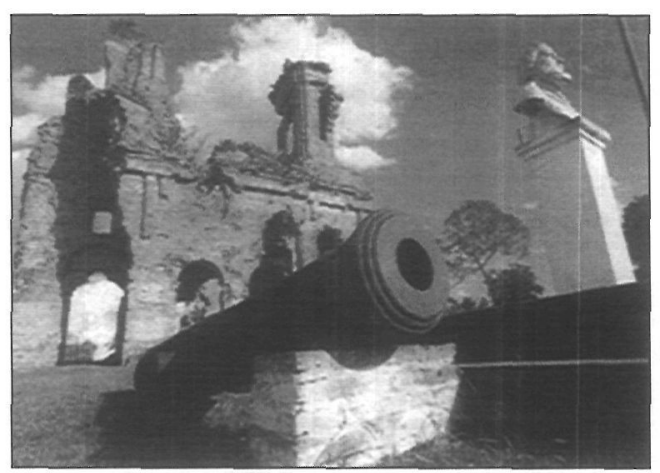

Ruinas de Humaitá (Foto de archivo de Jorge Rubbiani). prestigio y sacar provecho material ${ }^{3}$.

Cecilio Báez, escritor y político liberal paraguayo, sintetizó, en aquel entonces, el carácter del movimiento de recuperación de la imagen de Solano López: «Es simplemente una empresa mercantil, de ganancia, en la que creen los hijos de Linch (sic) que adulan a los poderosos» ${ }^{4}$.

La ideología lopizta no solamente defendió el rol histórico de Francisco Solano López, sino también de los gobernantes autocráticos que le antecedieron: José Gaspar Rodríguez de Francia y Carlos Antonio López. Esa ideología se oponía a los valores defendidos por el partido liberal, el cual se resistía a aceptar los valores tradicionales de la sociedad paraguaya y tenía los ojos puestos en el cosmopolitismo de Buenos Aires. La modernidad de los liberales se oponía al perfil rural del Partido Colorado, cuyo líder principal, el general Benardino Caballero, había peleado en la guerra de 1865-70 como hombre allegado a Solano López. Los colorados se creían nacionalistas y acusaban a los liberales de reflejar valores extranjeros. Para los colorados, los liberales eran "legionarios", es decir, miembros de la Legión Paraguaya, la pequeña fuerza militar de exiliados paraguayos que había peleado al lado de los aliados contra López.

A principios del siglo $\mathrm{XX}$, el ambiente intelectual paraguayo era dominado por un intransigente nacionalismo lopizta que no aceptaba críticas. Ese era el tema de los intelectuales paraguayos de aquella época, de la Generación de 1900, responsables por trabajos históricos que en gran parte idealizaban la sociedad paraguaya de la época autoritaria (18111870). No escribían cuentos ni novelas tampoco. Ignacia, la primera novela paraguaya, fue escrita en 1905 por José Rodríguez Alcalá, un
3

Relarório Polífico sobre o Paraguai (Confidencial), por Arthur dos Guimarães Bastos, $2^{\circ}$ Secrelário da Legação em Assunção. Assunção, 5.10.1931. Arquivo Histórico do Ministério das Relações Exteriores do Brasil (Rio de Janeiro), 201-4-6.

4

BÁEZ, Cecilio. «La tirania de Solano López; su aspecto comercial» en JUNTA PATRIÓTICA PARAGUAYA. El mariscal Francisco Solano López. Asunción: Junta Patriótica Paraguaya, 1926, p. 133.

El nacionalismo lopizta paraguayo FRANCISCO F. MONTEOLIVA DORATIOTO 


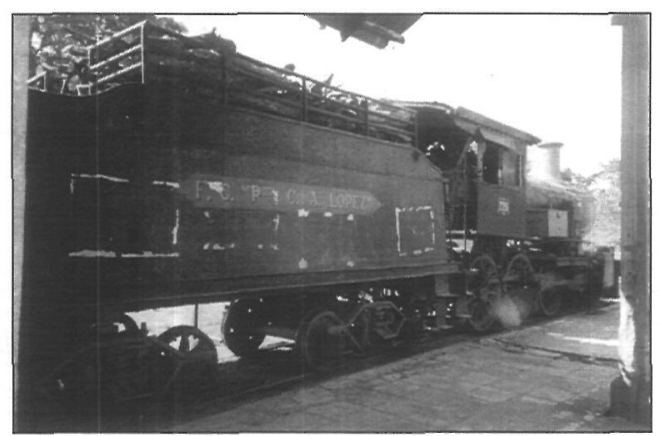

Locomotora. C.A. López. (Foto: Mar Langa). argentino que se había establecido en Asunción. La obra no tuvo acogida entusiasta, puesto que contenía críticas sociales en vez de idealizar la sociedad local. Por el mismo motivo, tampoco hubo buena acogida para la prosa y narración de otro escritor extranjero residente en Asunción: el español Rafael Barret. Los 5 CASTRO, Claude. Historia y Ficción: Caballero de Guido Rodriguez Alcalá. Asunción: Editorial Don Bosco, 1997, pág. 39.

\section{6}

GONZÁLEZ, Natalicio. El Paraguay Eterno. Asunción: Cuadernos Republicanos, 1986, pág. 113.

7

HERKEN KRAUER, Juan Carlos; GIMENEZ DE HERKEN, María Isabel. Gran Bretaña y la guerra de la Triple Alianza. Asunción: Editorial Arte Nuevo, 1982.

trabajos de ambos no glorificaban a Solano López y tampoco a los dos dictadores que lo precedieron.

En las tres primeras décadas del siglo XX, el lopizmo se hizo fuerte y se convirtió en la ideología del Partido Colorado. En 1936, el coronel Rafael Franco ascendió al poder. Tras derrocar al presidente liberal Eusebio Ayala, dictó decreto por el que Solano López se volvió héroe nacional. La predicación de O'Leary se hizo oficial y su nacionalismo dogmático y estatista estaba en armonía con la dictadura de Franco. El culto que se rendía a Solano López mostraba una concepción de estado favorable al régimen de fuerza franquista, puesto que en el culto a Solano López el rol del ejército era trascendental:

no son las instituciones, sino las gestas militares, las que dan cuerpo a la nación. Guiado por un jefe heroico, el ejército encarna naturalmente los intereses del país y es al mismo tiempo el encargado de luchar contra el enemigo «interior» $y$ «exterior» ${ }^{5}$.

Un año antes, en 1935, Natalicio González, escritor y político, había publicado el libro El Paraguay Eterno, en el que se intentaba demostrar que el liberalismo era un pensamiento exótico en el país y que habría una sola «esencia nacional», resultante de la tríada «tierra, raza e historia». Para González, el liberalismo era una doctrina contraria a la naturaleza de la sociedad paraguaya y tenía por objeto arruinar el país. Para salvarse, el Paraguay:

Necesita estrangular el liberalismo sin piedad, con fría decisión. Así tornará a ser la nación grande y fuerte que fundó la civilización en el Río de la Plata. La doctrina liberal es el veneno que emponzoña el alma de la patria ${ }^{6}$.
González fue presidente del Paraguay durante cinco meses, de agosto de 1948 a enero de 1949. Si bien es cierto que su presencia en el poder fue efímera, su influencia sobre el nacionalismo paraguayo fortaleció en el Partido Colorado la ideología favorable al régimen político autoritario y a la intervención del estado en la sociedad. Una ideología que rechazaba las concepciones liberales, políticas y económicas. Alfredo Stroessner, dictador colorado entre 1954 y 1989, heredó esa ideología y la adaptó al contexto internacional y regional de la guerra fría, de combate al comunismo, a fin de fortalecer su propio poder personal.

La mezcla de nacionalismo y lopizmo se hizo ideología omnipresente apoyada por el Estado. A. Stroessner se las daba de continuador de Solano López, pues según Claude Castro «como él, es militar; como él, gobierna de manera autoritaria por el bien de la patria. Todo opositor se considera traidor, 'legionario' a sueldo de potencias extranjeras.»

El nacionalismo lopizta se fue más allá de las fronteras. Atilo Garcia Mellid y José María Rosa, historiadores argentinos que abogaban por el revisionismo histórico de O'Leary, fueron recibidos y condecorados por Stroessner, en 1958. En las décadas de 60 y 70 surgió, en el Río de La Plata, el enfoque «antiimperialista» del nacionalismo lopizta, por el que se atribuyó el origen de la Guerra del Paraguay a la confrontación entre dos estrategias de crecimiento: la paraguaya, sin dependencia de los centros capitalistas; y las de Argentina y Brasil, dependientes del ingreso de los recursos financieros y tecnológicos extranjeros. Esos dos países habrían sido manipulados por los intereses de Gran Bretaña, la mayor potencia capitalista de entonces, con la intención de aniquilar el desarrollo autónomo paraguayo. Esos argumentos no se sostienen históricamente, según lo demuestran, entre otros estudiosos, Herken Krauer y Giménez de Herken, en el libro Gran Bretaña y la Guerra de la Triple Alianza?.

Echar la culpa a Gran Bretaña por la guerra de 1865-1870 dio al conflicto un carácter ideológico y permitió que se retratara a Francisco Solano López como héroe antiimperialista. Ese carácter viabilizó la aceptación del nacionalismo lopizta por parte de la intelectualidad latinoamericana de izquierda. De hecho, en Sudamérica, las décadas del 60 y 70 es- 
tuvieron enmarcadas por gobiernos militares. En la lucha contra el autoritarismo había necesidad de socavar sus bases ideológicas. Por ello, el nacionalismo lopizta antiimperialista fue tan exitoso entre los intelectuales: por atacar el pensamiento liberal, de conformidad con las acciones de militares golpistas que echaron abajo la democracia y las instituciones so pretexto de defenderlas.

Al fin y al cabo, Bartolomé Mitre, presidente de Argentina, que luchó contra Solano López, fue destacada figura del liberalismo de su país. En Brasil, donde los militares ocuparon el poder entre 1964 y 1985, Caxias e Tamandaré, jefes de las fuerzas brasileñas en la guerra, se hicieron patronos del ejército y de la marina, respectivamente. Además, en las entrelíneas de los trabajos revisionistas de izquierda se puede notar una similitud entre la Cuba socialista, aislada en el continente americano y hostilizada por los Estados Unidos, y el Paraguay de las dictaduras «progresistas» y víctima de Gran Bretaña, la gran potencia de entonces.

El nacionalismo lopizta se impuso en $\mathrm{Pa}-$ raguay, aunque los liberales tenían sus propios héroes en la Guerra del Chaco contra Bolivia, la cual tuvo lugar entre 1932 y 1936, bajo la presidencia del liberal Eusebio Ayala. En esa guerra, a diferencia de aquella contra la Triple Alianza, Paraguay no fue derrotado. Además, el conflicto se produjo durante la presidencia de un civil elegido por el pueblo. Sin embargo, a la dictadura de Alfredo Stroessner no le interesaba la apología de héroes civiles y de la eficiencia del Estado liberal; más bien deseaba promover la ideología autoritaria y militarista del nacionalismo lopizta, que se volvió la ideología oficial del Estado stronista.

Respaldado por las instituciones estatales, ese nacionalismo se impuso por la propaganda sistemática, por la persecución al pensamiento crítico en la universidad, por la restricción de la libertad de prensa, y por la inhibición a la investigación histórica con base metodológica científica. A consecuencia de esos actos, hasta los años 80 , la sociedad paraguaya tuvo un conocimiento distorsionado del proceso histórico del país. Había una percepción irreal de sus relaciones internacionales en el pasado así como de su rol en el contexto regional. Se inculcaba la idea de que cabría a caudillos de personalidad fuerte la conducción del Paraguay.

La cohibición a la investigación resultó en el mantenimiento de la ficción histórica nacionalista construida por Juan E. O'Leary y robustecida por la versión del imperialis-

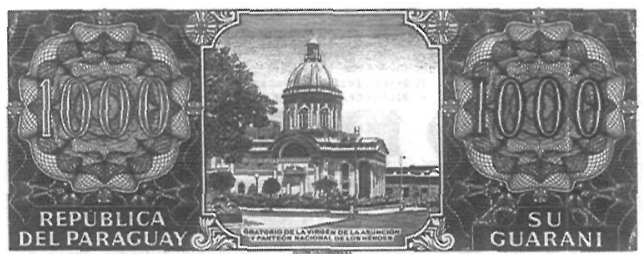

Panteón de los Héroes en billete de 1.000 guaraníes. mo inglés. $\mathrm{La}$ tan repetida

ficción terminó por ganar la apariencia de realidad. Por lo mismo, en 1982 Augusto Roa Bastos escribió que Paraguay, hacia mediados del siglo XIX, había alcanzado «una efectiva independencia y su autonomía económica». Según Roa Bastos, el país fue arrastrado por la Triple Alianza a la guerra tramada y financiada por la «Política de dominación del imperio británico»8.

En 1970, en pleno auge de la dictadura de Stroessner, le tocó a una novela cuestionar el obsesivo nacionalismo paraguayo. En ese año, en el centenario del final de la guerra de la Triple Alianza, el joven escritor Lincoln Silva publicó la novela Rebelión Después, en la que se valía de la ironía hacia el contenido de ese nacionalismo:

Eleuterio, como todos los paraguayos, se sentía mucho más paraguayo que todo el resto. Las causas de su orgullo nativo se remontaban al período guerrero; es decir, a todo el pasado, que no era sino un inmenso campo de batalla racionado por el tiempo. Acá, los únicos que engordan son los cuervos, y como nadie quiere enorgullecerse de ser descendiente de pájaro negro, todo el mundo se vanagloria de sus muertos, que tal vez sean los muertos de uno?.

Sin embargo, tres años después, el líder político liberal Domingo Laíno, «un legionario», acudió al nacionalismo lopizta. A lo mejor, lo hizo por provecho político, pero puso de manifiesto cómo la tolerancia hacia el autoritarismo se había pegado a la sociedad paraguaya. En 1973, al pronunciar un discurso en el parlamento paraguayo contra el tratado de Itaipú, firmado entre Brasil y Paraguay, Laíno hizo elogio de José Gaspar Rodríguez de Francia, Carlos Antonio López y Francisco Solano López. En 1989, en el prólogo de la segunda edición de su libro Paraguay: de la independencia a la dependencia (bistoria del saqueo inglés en el Paraguay de la posguerra), Laíno sostuvo que la guerra entre su país y la Triple Alianza fue «imperialista» $\mathrm{y}$ «neocolonial» 10 .
8 Apud. RODRÍGUEZ ALCALÁ, Guido. «Revisionismo histórico y autoritarismo», Múltipla. Brasilia: Faculdades Integradas UPIS, 11 (dez. 2001), p. 80

9

Apud. RODRÍGUEZ-ALCALÁ, Hugo. La incógnita del Paraguay y otros ensayos. Asunción: Arte Nuevo, 1987, p. 68.

10

Guido RODRÍGUEZ ALCALÁ, p. 80.

LAíNO, Domingo. Paraguay: de la independencia a la dependencia. Asunción: Inter-continental, 1989. $2^{\mathrm{g}} \mathrm{ed}$.
El nacionalismo lopizta paraguayo FRANCISCO F. MONTEOLIVA DORATIOTO 
11

Caballero. Buenos Aires: Editorial Sudamericana, 1987; CabaHero Rey. Asunción: RP Ediciones, 1988; Ideología autoritaria Asunción: RP Ediciones, 1987 La Segunda República paraguaya (1869-1906). Asunción: ArteNuevo Editores, 1985.

12

Guido RODRÍGUEZ ALCALÁ, «Revisionismo histórico y autoritarismo», p. 83.
Hacia fines de los años 80 , cuando se producía el destape en los países vecinos de Paraguay y empezaba el desplome de la estructura todavía represiva de Stroessner, varios intelectuales paraguayos cuestionaron el nacionalismo lopizta. Guido Rodríguez Alcalá lo hizo con ironía en las novelas Caballero y Caballero Rey y en el ensayo Ideología Autoritaria. Ricardo Caballero Aquino en la Segunda República Paraguaya (1869-1906), de 1985, demostró la fragilidad de la historiografía nacionalista ${ }^{11}$. Esos y otros trabajos, que cuestionaban el nacionalismo autoritario, eran parte del proceso de cambios que estaba en marcha en Paraguay y que resultó en el derrocamiento del régimen de Alfredo Stroessner, tras el golpe militar de 1989, conducido por el general Rodríguez.

A partir de entonces, se estableció la democracia, aunque frágil y superficial, representada por la elecciones presidenciales que se celebraron en 1994. Fue como aire puro y nuevo vigor para el Paraguay. Al igual que el sol que entra por las ventanas recién abiertas de una casa que quedó cerrada por años, destruyendo el moho acumulado, el nacionalismo lopizta ha sido corroído en sus bases por la democratización paraguaya. Según Guido Rodríguez Alcalá:
Las cosas han cambiado bastante, porque se concede mayor interés al presente y menor al pasado. Las discusiones 'históricas' (lopizmo versus antilopizmo) van perdiendo interés. La referencia a Francia \& López en los los discursos oficiales ha disminuido ${ }^{12}$.

El aislamiento paraguayo, en sus diferentes dimensiones, llegó a su fin debido a un conjunto de factores: la llegada de la democracia, la facilidad de contacto con el resto del mundo, gracias a las nuevas tecnologías de comunicación y al proceso de integración regional del Mercosur. El aislamiento había sido una protección para el crecimiento del nacionalismo lopizta, el cual reforzó ideológicamente ese aislamiento al darle contenido xenófobo. Hoy, un reto con el que Paraguay debe enfrentarse es el ejercicio de un nacionalismo que sea instrumento, a la vez, de la valoración de su cultura y de la colaboración en la integración internacional. Integrarse sin perder la identidad es un reto considerable, puesto que el ambiente paraguayo en los últimos años, de crisis económica y de tensión política, influye negativamente sobre la autoestima nacional. 